\title{
LETTERS
}

\section{Assisted dying for patients with psychiatric disorders}

I fully agree with Dembo and Smith's article on assisted dying for patients with psychiatric disorders. ${ }^{1}$

Excluding mental illness amounts to discrimination. Certainly, the illness should be present consistently and continuously for a period of at least three years, and the patient would have not responded adequately to conventional treatments. Quality of life has to be significantly impaired and the patient, when mentally competent, has to decide on dying.

We must never forget the fact that it is the patient - and not necessarily the caregivers - who knows best of the suf- fering. Neither the egos or the affiliations of caregivers, the potential of "future discoveries," nor administrative red tape should prolong the suffering.

\section{Lal Fernando MD}

Windsor Adult ADD and Memory

(Alzheimer) Clinic; Schulich School of

Medicine and Dentistry, Windsor, Ont.

- Cite as: CMAJ 2017 March 13;189:E413.

doi: 10.1503/cmaj.732757

\section{Reference}

1. Dembo J, Smith D. Assisted dying for patients with psychiatric disorders [letter]. CMAJ 2016;188:1036.

Competing interests: None declared. 